Exp. Anim. 68(4), 429-434, 2019

-Original-

\title{
Measurements of body surface area and volume in male Japanese White rabbits using a computed tomography scanner: comparison with male New Zealand White rabbits
}

\author{
Tadashi ITOH $^{1)}$, Mifumi KAWABE(2), Takahiko NAGASE1), Katsumi ENDO'1), \\ Masafumi MIYOSHI ${ }^{3)}$ and Kazuro MIYAHARA ${ }^{3)}$ \\ 1)Nihon Bioresearch Inc., 6-104 Majima, Fukujucho, Hashima, Gifu 501-6251, Japan \\ 2) Animal Medical Center, Faculty of Applied Biological Sciences, Gifu University, 1-1 Yanagido, Gifu 501-1193, \\ Japan \\ 3) Veterinary Medical Center, Obihiro University of Agriculture and Veterinary Medicine, Inadacho, Obihiro, \\ Hokkaido 080-8555, Japan
}

\begin{abstract}
The body surface area (BSA) of animals has generally been estimated by multiplying the $k$ value by the measured body weight (BW) raised to the power of 2/3 (Meeh's formula). In mathematical terms, the assumption that the density and body shape of animals are essentially constant means that the BSA is proportional to BW2/3. In this study, we measured the BSA and volume of 50 male Japanese White rabbits (JW) at 10 to 54 weeks of age using a computed tomography scanner, then calculated the $k$ value, density, and sphericity. The variations in these parameters were then analyzed in relation to growth. The obtained results indicated that the $k$ value was negatively correlated to BW, and that this negative correlation was mainly due to the variation in density. Based on the regression analysis, we propose the following linear regression equation for calculating the $k$ value in male JW at $10-54$ weeks of age: the $k$ value $=14.602-0.959 \times \mathrm{BW}[\mathrm{kg}]$. The calculated values ranged from 10.9 to 12.7 (working BW range: 1.98 to $3.81 \mathrm{~kg}$ ). The $k$ value of male New Zealand White rabbits (NZW) determined in our previous study and that of male JW in the present study were compared. It was revealed that the $k$ value of male JW was larger than that of male NZW. We concluded that different breeds of rabbits express different $k$ values.
\end{abstract}

Key words: body surface area, computed tomography, CT scanner, Japanese White rabbit, rabbit

\section{Introduction}

Rabbit is one of the most major laboratory animals and has been used for many nonclinical studies such as toxicity, reproduction toxicity, local tolerance, pyrogen test, and pharmacology studies. New Zealand White rabbits (NZW) are the most widely used breed as laboratory rabbits in the world, but in Japan the use of Japanese
White rabbits (JW) is the most frequent and the number of use of NZW is the second [6]. Therefore, it is important to investigate and compare the various parameters between JW and NZW for a unified interpretation of the test results obtained with each breed.

The body surface area (BSA) of an organism is one of the parameters used for evaluating physiological functions, such as an essential requirement in calculating the

(Received 25 January 2019 / Accepted 3 April 2019 / Published online in J-STAGE 14 May 2019)

Corresponding author: T. Itoh.e-mail: ito.tadashi@nisshin.com

(c) $(-)$ This is an open-access article distributed under the terms of the Creative Commons Attribution Non-Commercial No Derivatives (by-nc-nd) License <http://creativecommons.org/licenses/by-nc-nd/4.0/>.

(C)2019 Japanese Association for Laboratory Animal Science 
cardiac index [5], assessing the basal metabolic rate [3, 10], and determining the burn surface area as a percentage of the total. BSA has also been used as a criterion for drug dosage determination since the 1950s [15]. In drug development, the no observed adverse effect levels in laboratory animal species have been converted to human equivalent doses using scaling factors. Normalization by BSA (i.e., conversion of a dosage from $\mathrm{mg} / \mathrm{kg}$ to $\mathrm{mg} / \mathrm{m}^{2}$ ) is an appropriate method for extrapolating doses between species. The Food and Drug Administration Center for Drug Evaluation and Research guidance recommends the use of BSA to estimate starting doses in the initial clinical trials for therapeutics in volunteer subjects [2]. In addition, the procedures for assessing dermal toxicity are described in the guidelines issued by the Organization for Economic Cooperation and Development and these guidelines recommend that the test substance be applied to not less than $10 \%$ of the total BSA [12-14]. Thus, accurately determining the BSA of laboratory animals is extremely important.

The BSA of animals has generally been estimated by multiplying a constant by the measured body weight (BW) raised to the power of $2 / 3$ [11]. The $k$ values (100 $\times \mathrm{BSA}\left[\mathrm{m}^{2}\right]=k \times \mathrm{BW}[\mathrm{kg}]^{2 / 3}$, i.e., Meeh's formula) for various animal species have been reported and used to extrapolate the test results between species. To date, the $k$ values for rabbits have been calculated in various ways; $k$ values of 5.7 to 10.0 were determined by use of skinning and triangulation reported by Spector [16], while values of 12.0 to 12.9 were reported by Fougère and Wynn who did not show the method of BSA determination [4], and Zehnder et al. reported a $k$ value of 9.9 analyzed the Computed tomography (CT) images using their own procedure [17]. Additionally, Bai et al. reported 7-month old male JW (working BW range: 2.5 to $3.0 \mathrm{~kg}$ ) $\mathrm{k}$ values of 11.30 to 11.35 determined by use of paper cover and skinning [1]. However, it has been pointed out that the BSA computed by Zehnder's procedure may be smaller than the actual value [9] and that the accuracy and reproducibility of other traditional methods may have limitations [7].

CT scanners can generate detailed 3-dimensional (3D) images of objects, thus, with appropriate analysis, CT images provide more accurate BSA estimates than traditional measurement techniques. Previously, we determined the BSAs of laboratory miniature pigs and NZW using a CT scanner and 3D analysis software based on the computer graphics algorithm known as Marching
Cubes and Discriminant Analysis Method, and calculated the $k$ values for peripubertal- or mature-miniature pigs, juvenile miniature pigs, and NZW as 7.98 [7], 8.58 [8], and 11.0 [9], respectively. Unlike the traditional measurement techniques, analyzing $\mathrm{CT}$ images does not depend on the skill of an operator, thus, the results are extremely reproducible. Therefore, this measurement method is suitable for comparing the $k$ values among species or breeds.

In mathematical terms, the assumption that the density and body shape of animals are essentially constant means that the $\mathrm{BSA}$ is proportional to $\mathrm{BW}^{2 / 3}$. In other words, density and sphericity (i.e., index of the body shape) are inversely correlated with the $k$ value. In the present study, we measured the BSA and volume $(V)$ of male JW from CT images, then calculated the $k$ value, density, and sphericity. The variations in these parameters were then analyzed in relation to growth. And the $k$ value of male NZW determined in our previous study and that of male JW in the present study were compared.

\section{Materials and Methods}

\section{Animals}

JW (Kbl:JW) were obtained from Kitayama LABES Co., Ltd. (Nagano, Japan). The BSA and $V$ were measured for the 50 males (at 10-54 weeks of age) that had been used in other non-clinical studies and euthanized by anesthesia with sodium pentobarbital according to the protocols of the previous studies. No critical abnormalities in clinical signs or BW changes were noted in these rabbits during the time that they were alive. All studies were conducted in compliance with the Guidelines for Management and Welfare of Experimental Animals of Nihon Bioresearch Inc.

\section{Experimental procedures}

The BSA was measured as described previously [9]. Briefly, the body of each rabbit was set in the prone position for whole-body CT scanning on the day of euthanasia. Images were obtained using a multislice CT scanner (Alexion TSX 033A, Toshiba Medical Systems Co., Ltd., Tochigi, Japan). The slice thickness and the reconstruction interval were $3 \mathrm{~mm}$ and $1.5 \mathrm{~mm}$, respectively. The BSA of each animal was determined from the 3D CT images (Fig. 1) using high-speed 3D analysis software (TRI-3D/VOL, Ratoc System Engineering Co., Ltd., Tokyo, Japan). The $k$ value was then calculated 

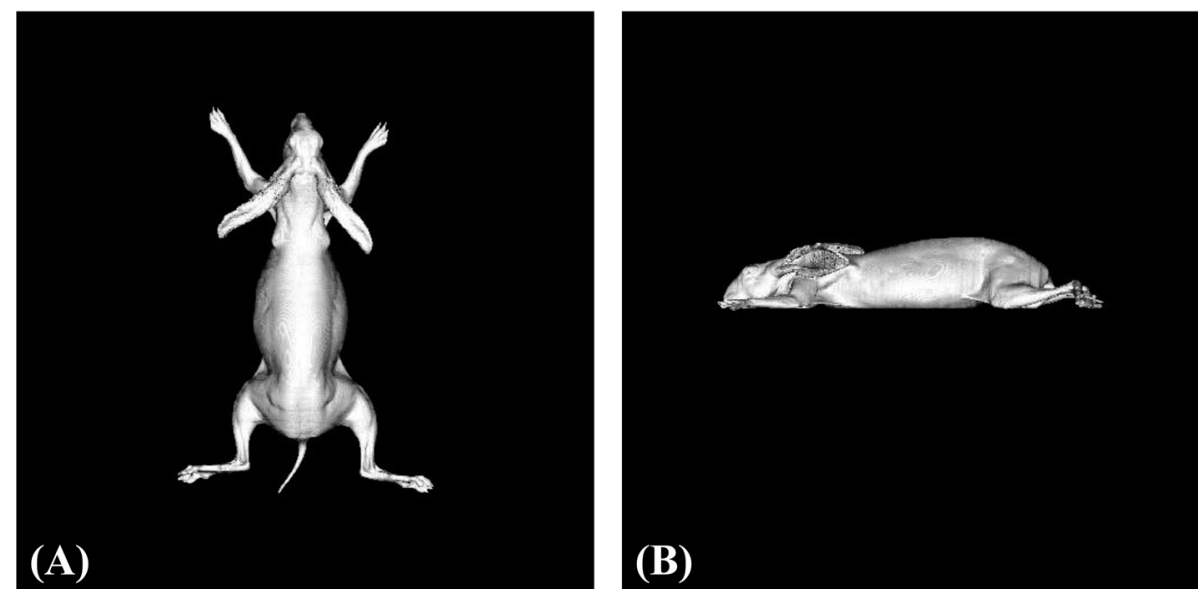

Fig. 1. Computed tomography (CT) images of male Japanese White rabbits (JW). (A) JW in dorsal aspect. (B) In lateral side.

based on the determined BSA value.

The $V$ of each animal was determined from axial multiplanar reconstruction of the CT images. The total area of each section of the CT images was calculated using image processing software (Win ROOF, Mitani Co., Fukui, Japan) and multiplying the value by $1.5 \mathrm{~mm}$ (the reconstruction interval). After $V$ had been determined, the density (= BW $[\mathrm{kg}] / V[1])$ and the sphericity (= $\left.\pi^{1 / 3}[6 V]^{2 / 3} / 100 \mathrm{BSA}\right)$ were calculated.

All statistical procedures were performed using statistical software (Pharmaco Basic, Scientist Press Co., Ltd., Tokyo, Japan). The significant figure was set to 3 digits.

\section{Results and Discussion}

\section{Measured and calculated values}

As shown in Table 1, the BWs of the 50 male JW ranged from 1.98 to $3.81 \mathrm{~kg}$ (mean: $2.84 \mathrm{~kg}$, median: $2.84 \mathrm{~kg}$ ), and their mean age was 24.3 weeks (median: 18.0 weeks). There was no obvious difference between the BWs of JW at 10 to 18 weeks of age in the present study and those in the background data provided by the breeder (working age range: 6 to 20 weeks, data not shown). The BSA and the $V$ values ranged from 0.193 to $0.270 \mathrm{~m}^{2}$ and from 2.05 to 3.611 , respectively.

The mean $\pm \mathrm{SD}, \mathrm{CV}$, and the median for the $k$ value were $11.9 \pm 0.6,5.29 \%$, and 11.9 , respectively; these same statistics calculated for density were $0.98 \pm 0.07$, $6.90 \%$, and 0.96 , respectively; and for sphericity, the respective statistics were $0.414 \pm 0.018,4.46 \%$, and

\subsection{5 (Table 1).}

The correlation coefficient $(r)$ between the BWs and the $k$ values, between the BWs and the densities, or between the BWs and the sphericities was $-0.770,0.692$, or 0.186 , respectively, and the probability $(P)$ was 0.000 , 0.000 , or 0.195 , respectively (Fig. 2). These results indicated that the $k$ value was negatively correlated to $\mathrm{BW}$, and that this negative correlation was mainly due to the variation in density. The $r$ between the BWs and the $k V$ values $\left(100 \times \mathrm{BSA}\left[\mathrm{m}^{2}\right]=k V \times V[1]^{2 / 3}\right)$ of the male $\mathrm{JW}$, and the $P$ were -0.214 and 0.135 , respectively (Fig. 2). The absolute value of $r$ for the $k V$ value is obviously smaller than that for the $k$ value. More precisely, the change in body composition that occurs with growth affected the $k$ value of male JW at 10-54 weeks of age.

\section{$k$ value in male JW at 10-54 weeks of age}

Based on the regression analysis (response variable: $k$ value and explanatory variable: BW) by the least squares method, we propose the following linear regression equation for calculating the $k$ value in male JW at $10-54$ weeks of age: the $k$ value $=14.602-0.959 \times \mathrm{BW}$ [kg] (coefficient of determination: $R^{2}=0.592$ ). The calculated values ranged from 10.9 to 12.7 (working BW range: 1.98 to $3.81 \mathrm{~kg}$ ). These calculated values $\times 100 /$ the $k$ values ranged from $93 \%$ to $112 \%$ (Table 1 ).

\section{Comparison with NZW in our previous report}

In our previous report [9], we measured the BSA and $V$ of NZW using the same methods as the present study. The mean $k$ value, density, and sphericity of 42 male 
Table 1. Body weight (BW), age, body surface area (BSA), $V, k$ value, density, sphericity, and $k V$ value in male Japanese White rabbits (JW)

\begin{tabular}{|c|c|c|c|c|c|c|c|c|c|}
\hline & BW (kg) & Age (week) & $\operatorname{BSA}\left(m^{2}\right)$ & $V(1)$ & $k$ value & $\begin{array}{l}\text { Density } \\
(\mathrm{kg} / \mathrm{l})\end{array}$ & Sphericity & $k V$ value & $14.602-0.959 \times \mathrm{BW}^{*}$ \\
\hline & 1.98 & 10 & 0.201 & 2.09 & 12.7 & 0.95 & 0.393 & 12.3 & $12.7(100 \%)$ \\
\hline & 2.02 & 10 & 0.200 & 2.05 & 12.5 & 0.99 & 0.390 & 12.4 & $12.7(102 \%)$ \\
\hline & 2.10 & 10 & 0.216 & 2.23 & 13.2 & 0.94 & 0.382 & 12.7 & $12.6(95 \%)$ \\
\hline & 2.16 & 10 & 0.215 & 2.24 & 12.9 & 0.96 & 0.385 & 12.6 & $12.5(97 \%)$ \\
\hline & 2.18 & 10 & 0.212 & 2.32 & 12.6 & 0.94 & 0.400 & 12.1 & $12.5(99 \%)$ \\
\hline & 2.22 & 10 & 0.224 & 2.37 & 13.2 & 0.94 & 0.384 & 12.6 & $12.5(95 \%)$ \\
\hline & 2.28 & 10 & 0.217 & 2.39 & 12.5 & 0.95 & 0.398 & 12.1 & $12.4(99 \%)$ \\
\hline & 2.30 & 14 & 0.193 & 2.59 & 11.1 & 0.89 & 0.473 & 10.2 & $12.4(112 \%)$ \\
\hline & 2.30 & 14 & 0.214 & 2.54 & 12.3 & 0.91 & 0.421 & 11.5 & $12.4(101 \%)$ \\
\hline & 2.32 & 10 & 0.214 & 2.30 & 12.2 & 1.01 & 0.394 & 12.3 & $12.4(102 \%)$ \\
\hline & 2.32 & 10 & 0.224 & 2.43 & 12.8 & 0.95 & 0.390 & 12.4 & $12.4(97 \%)$ \\
\hline & 2.35 & 14 & 0.214 & 2.61 & 12.1 & 0.90 & 0.428 & 11.3 & $12.3(102 \%)$ \\
\hline & 2.36 & 14 & 0.223 & 2.62 & 12.6 & 0.90 & 0.412 & 11.7 & $12.3(98 \%)$ \\
\hline & 2.38 & 14 & 0.211 & 2.60 & 11.8 & 0.92 & 0.433 & 11.2 & $12.3(104 \%)$ \\
\hline & 2.40 & 14 & 0.214 & 2.49 & 11.9 & 0.96 & 0.415 & 11.6 & $12.3(103 \%)$ \\
\hline & 2.48 & 14 & 0.226 & 2.80 & 12.3 & 0.89 & 0.425 & 11.4 & $12.2(99 \%)$ \\
\hline & 2.49 & 14 & 0.219 & 2.70 & 11.9 & 0.92 & 0.428 & 11.3 & $12.2(103 \%)$ \\
\hline & 2.52 & 13 & 0.217 & 2.75 & 11.7 & 0.92 & 0.437 & 11.1 & $12.2(104 \%)$ \\
\hline & 2.59 & 14 & 0.246 & 3.07 & 13.0 & 0.84 & 0.415 & 11.6 & $12.1(93 \%)$ \\
\hline & 2.61 & 14 & 0.223 & 3.07 & 11.8 & 0.85 & 0.458 & 10.6 & $12.1(103 \%)$ \\
\hline & 2.64 & 13 & 0.225 & 2.70 & 11.8 & 0.98 & 0.417 & 11.6 & $12.1(103 \%)$ \\
\hline & 2.66 & 13 & 0.233 & 2.81 & 12.1 & 0.95 & 0.413 & 11.7 & $12.1(100 \%)$ \\
\hline & 2.73 & 54 & 0.233 & 2.56 & 11.9 & 1.07 & 0.388 & 12.5 & $12.0(101 \%)$ \\
\hline & 2.79 & 14 & 0.237 & 3.05 & 12.0 & 0.91 & 0.429 & 11.3 & $11.9(99 \%)$ \\
\hline & 2.80 & 13 & 0.238 & 3.05 & 12.0 & 0.92 & 0.427 & 11.3 & $11.9(99 \%)$ \\
\hline & 2.88 & 18 & 0.240 & 3.09 & 11.9 & 0.93 & 0.427 & 11.3 & $11.8(99 \%)$ \\
\hline & 2.91 & 54 & 0.244 & 2.71 & 12.0 & 1.07 & 0.385 & 12.6 & $11.8(98 \%)$ \\
\hline & 2.93 & 18 & 0.249 & 3.05 & 12.2 & 0.96 & 0.408 & 11.8 & $11.8(97 \%)$ \\
\hline & 2.99 & 18 & 0.259 & 3.20 & 12.5 & 0.93 & 0.405 & 11.9 & $11.7(94 \%)$ \\
\hline & 3.03 & 18 & 0.237 & 3.11 & 11.3 & 0.97 & 0.435 & 11.1 & $11.7(104 \%)$ \\
\hline & 3.03 & 18 & 0.256 & 3.22 & 12.2 & 0.94 & 0.412 & 11.7 & $11.7(96 \%)$ \\
\hline & 3.07 & 18 & 0.250 & 3.28 & 11.8 & 0.94 & 0.427 & 11.3 & $11.7(99 \%)$ \\
\hline & 3.10 & 27 & 0.247 & 2.99 & 11.6 & 1.04 & 0.406 & 11.9 & $11.6(100 \%)$ \\
\hline & 3.10 & 54 & 0.245 & 2.89 & 11.5 & 1.07 & 0.400 & 12.1 & $11.6(101 \%)$ \\
\hline & 3.12 & 27 & 0.243 & 3.02 & 11.4 & 1.03 & 0.416 & 11.6 & $11.6(102 \%)$ \\
\hline & 3.15 & 27 & 0.241 & 2.98 & 11.2 & 1.06 & 0.416 & 11.6 & $11.6(104 \%)$ \\
\hline & 3.22 & 27 & 0.234 & 3.03 & 10.7 & 1.06 & 0.433 & 11.2 & $11.5(107 \%)$ \\
\hline & 3.30 & 27 & 0.262 & 3.10 & 11.8 & 1.06 & 0.392 & 12.3 & $11.4(97 \%)$ \\
\hline & 3.31 & 27 & 0.258 & 3.33 & 11.6 & 0.99 & 0.418 & 11.6 & $11.4(98 \%)$ \\
\hline & 3.34 & 54 & 0.245 & 3.14 & 11.0 & 1.06 & 0.423 & 11.4 & $11.4(104 \%)$ \\
\hline & 3.36 & 27 & 0.255 & 3.23 & 11.4 & 1.04 & 0.414 & 11.7 & $11.4(100 \%)$ \\
\hline & 3.39 & 54 & 0.256 & 3.20 & 11.3 & 1.06 & 0.410 & 11.8 & $11.4(101 \%)$ \\
\hline & 3.43 & 27 & 0.261 & 3.35 & 11.5 & 1.02 & 0.415 & 11.7 & $11.3(98 \%)$ \\
\hline & 3.43 & 27 & 0.270 & 3.36 & 11.9 & 1.02 & 0.402 & 12.0 & $11.3(95 \%)$ \\
\hline & 3.46 & 54 & 0.248 & 3.17 & 10.8 & 1.09 & 0.421 & 11.5 & $11.3(105 \%)$ \\
\hline & 3.49 & 54 & 0.259 & 3.22 & 11.3 & 1.08 & 0.407 & 11.9 & $11.3(100 \%)$ \\
\hline & 3.54 & 27 & 0.262 & 3.36 & 11.3 & 1.05 & 0.414 & 11.7 & $11.2(99 \%)$ \\
\hline & 3.64 & 54 & 0.263 & 3.43 & 11.1 & 1.06 & 0.418 & 11.6 & $11.1(100 \%)$ \\
\hline & 3.79 & 54 & 0.264 & 3.57 & 10.9 & 1.06 & 0.428 & 11.3 & $11.0(101 \%)$ \\
\hline & 3.81 & 54 & 0.268 & 3.61 & 11.0 & 1.06 & 0.425 & 11.4 & $10.9(99 \%)$ \\
\hline Mean & 2.84 & 24.3 & 0.236 & 2.88 & 11.9 & 0.98 & 0.414 & 11.7 & \\
\hline SD & 0.50 & 16.1 & 0.020 & 0.40 & 0.6 & 0.07 & 0.018 & 0.5 & \\
\hline $\mathrm{CV}$ & & & & & $5.29 \%$ & $6.90 \%$ & $4.46 \%$ & $4.41 \%$ & \\
\hline Median & 2.84 & 18.0 & 0.238 & 3.01 & 11.9 & 0.96 & 0.415 & 11.7 & \\
\hline
\end{tabular}

*Percentage in parentheses is $(14.602-0.959 \times \mathrm{BW}) \times 100 / k$ value. 


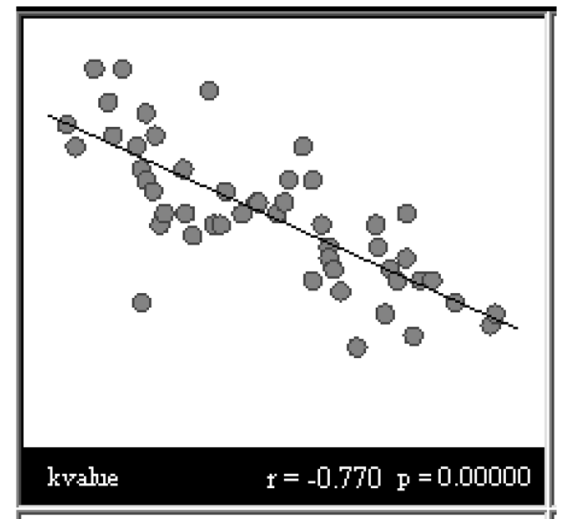

(A) $k$ value

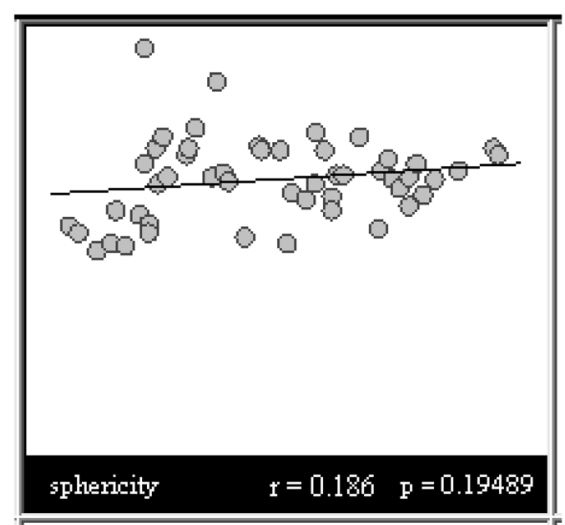

(C) sphericity

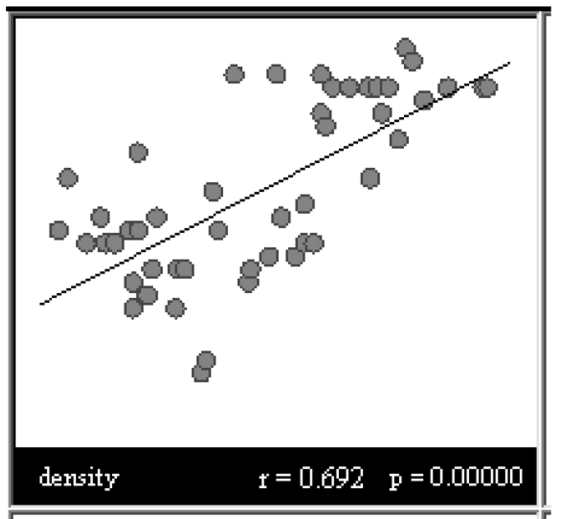

(B) density

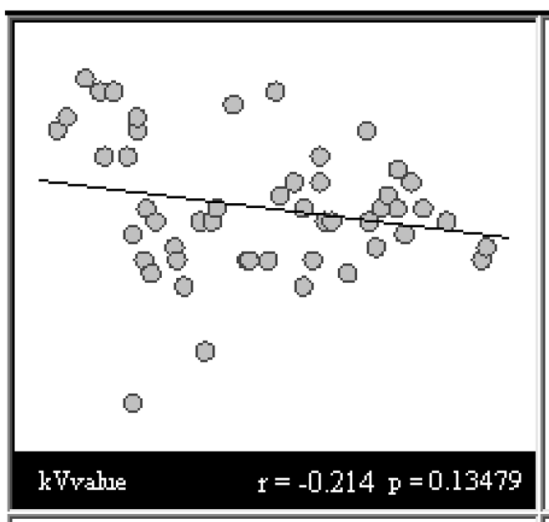

(D) $k V$ value

Fig. 2. Scatter diagrams representing the $k$ value (A), the density (B), the sphericity (C), or the $k V$ value (D) on the vertical axis and the body weight $(\mathrm{BW})$ on the horizontal axis in the male Japanese White rabbits (JW).

NZW at 11-41 weeks of age were 11.1, 1.05, and 0.421, respectively (working BW range: 2.22 to $3.69 \mathrm{~kg}$ ). Compared to NZW values, this study showed that the $k$ value in male JW was larger, while the density and sphericity were smaller. One reason for why the sphericity of JW was smaller is the longer ear and face dimensions of this breed compared to NZW. Furthermore, at 11 to 41 weeks of age, the $k$ value, density, and sphericity of male NZW essentially remained constant [9], whereas in the case of male JW, only sphericity remained constant; the $k$ value was negatively correlated with BW while density was positively correlated with BW. Therefore, as the BW of male JW from 10 to 54 weeks of age increased, the $k$ value and density approached the values of NZW.

From the above results, we concluded that different breeds of rabbits express different $k$ values. The accuracy and reproducibility of measuring the surface area and $V$ using our method was confirmed on the acrylic cuboids [9]. Therefore, our measurement method using a CT scanner is reliable. We propose that this measuring method be used to verify the $k$ values of other laboratory animals. Furthermore the $k$ values should be compared between breeds and gender.

\section{Conflict of Interest}

The authors declare that there is no conflict of interest.

\section{Acknowledgments}

The authors wish to thank all members of Nihon Bioresearch Inc., for their help and support during this study.

\section{References}

1. Bai, L., Huang, B., Chen, Y., Zhao, S., Fan, J. and Liu, E. 
2017. Determination of body surface area in Japanese White Rabbits. Scand. J. Lab. Anim. Sci. 43: 637-644.

2. Center for Drug Evaluation and Research 2005. Estimating the maximum safe starting dose in initial clinical trials for therapeutics in adult healthy volunteers. In: Guidance for Industry. https://wayback.archive-it.org/7993/20170403220541/ https:/www.fda.gov/ucm/groups/fdagov-public/@fdagovdrugs-gen/documents/document/ucm078932.pdf.

3. Dale, H.E. 1970. Energy metabolism. pp. 619-633. In: Duke's physiology of domestic animals, 8th ed. (Swenson, M.J., ed.), Cornel University Press, Ithaca.

4. Fougère, B.J., and Wynn, S.G. 2007. Herb manufacture, pharmacy and dosing. pp. 221-236. In: Veterinary Herbal Medicine. (Wynn S.G., and Fougère, B.J. eds.), Mosby, St. Louis.

5. Hall, J.E. 2011. Cardiac output, venous return, and their regulation. pp. 229-241. In: Textbook of medical physiology, Saunders, Philadelphia.

6. Inomata, T. 2018. Characteristics of each experimental animal. pp. 133-156. In: Laboratory animal science second edition. (Kyuwa S., ed.), Asakura publishing. Tokyo (in Japanese).

7. Itoh, T., Kawabe, M., Nagase, T., Endo, K., Miyoshi, M. and Miyahara, K. 2016. Body surface area measurement in laboratory miniature pigs using a computed tomography scanner. J. Toxicol. Sci. 41: 637-644. [Medline] [CrossRef]

8. Itoh, T., Kawabe, M., Nagase, T., Matsushita, H., Kato, M., Miyoshi, M. and Miyahara, K. 2017. Body surface area measurement in juvenile miniature pigs using a computed tomography scanner. Exp. Anim. 66: 229-233. [Medline] [CrossRef]

9. Itoh, T., Kawabe, M., Nagase, T., Koike, T., Miyoshi, M. and Miyahara, K. 2018. Measurements of body surface area and volume in laboratory rabbits (New Zealand White rabbits) using a computed tomography scanner. Exp. Anim. 67: 527-534. [Medline] [CrossRef]

10. Kleiber, M. 1965. Metabolic body size. pp. 427-435 In: Energy metabolism (Blaxter, K.L., ed.), Academic Press, London.

11. Meeh, K. 1879. Oberflächenmessungen des menschlichen Körpers. Z. Biol. 15: 425-458 (in German).

12. OECD 1981. Test No. 410: Repeated Dose Dermal Toxicity: 21/28-day Study. In: OECD Guidelines for the Testing of Chemicals, Section 4. http://www.oecd-ilibrary.org/ environment/test-no-410-repeated-dose-dermal-toxicity21-28-day-study_9789264070745-en.

13. OECD 1981. Test No. 411: Subchronic Dermal Toxicity: 90-day Study. In: OECD Guidelines for the Testing of Chemicals, Section 4. http://www.oecd-ilibrary.org/environment/test-no-411-subchronic-dermal-toxicity-90-daystudy_9789264070769-en.

14. OECD 2017. Test No. 402: Acute Dermal Toxicity. In: OECD Guidelines for the Testing of Chemicals, Section 4. http:// www.oecd-ilibrary.org/environment/test-no-402-acute-dermal-toxicity 9789264070585-en.

15. Pinkel, D. 1958. The use of body surface area as a criterion of drug dosage in cancer chemotherapy. Cancer Res. 18: 853-856. [Medline]

16. Spector, W.S. 1956. Constants for estimating surface area: mammals. p.175. In: Handbook of biological data. W. B. Saunders, Philadelphia.

17. Zehnder, A.M., Hawkins, M.G., Trestrail, E.A., Holt, R.W. and Kent, M.S. 2012. Calculation of body surface area via computed tomography-guided modeling in domestic rabbits (Oryctolagus cuniculus). Am. J. Vet. Res. 73: 1859-1863. [Medline] [CrossRef] 